\title{
Anatomia foliar de espécies epífitas de Orchidaceae
}

\author{
VIRGINIA DEL CARMEN OLIVEIRA ${ }^{1}$ e MARIA DAS GRAÇAS SAJO ${ }^{2,3}$
}

(recebido em 15/12/98; aceito em 28/04/99)

ABSTRACT - (Leaf anatomy of epiphyte species of Orchidaceae). The leaves have a spongy chlorenchyma and the smaller and larger vascular bundles are intercalated, in all Orchidaceae studied (Catasetum fimbriatum Lindl., Dichaea bryophila Rchb. f., Encyclia calamaria (Lindl.) Pabst, E. campestre Lindl., E. secundum Jacq., Miltonia flavescens Lindl., Pleurothallis smithiana Lindl., Stanhopea lietzei (Regel) Schltr. e Vanda tricolor Lindl.). Most of the leaves studied have sclerified cells close to both surfaces. Structural characters, which could be considered leaf adaptations to an epiphytic habit, were common for most species.

RESUMO - (Anatomia foliar de espécies epífitas de Orchidaceae). O mesofilo é formado por parênquima lacunoso e os feixes vasculares, maiores e menores, se dispõem intercaladamente, nas folhas de Orchidaceae estudadas (Catasetum fimbriatum Lindl., Dichaea bryophila Rchb. f., Encyclia calamaria (Lindl.) Pabst, Epidendrum campestre Lindl., E. secundum Jacq., Miltonia flavescens Lindl., Pleurothallis smithiana Lindl., Stanhopea lietzei (Regel) Schltr. e Vanda tricolor Lindl.). No mesofilo de quase todas as espécies ocorrem células esclerificadas adjacentes à epiderme, nas duas faces foliares. Também são comuns, nas folhas estudadas, caracteres estruturais que podem ser interpretados como adaptações ao hábito epifítico.

Key words - Leaf anatomy, Orchidaceae, epiphytism

\section{Introdução}

As Orchidaceae constituem uma das maiores famílias de plantas floríferas e representam o grupo mais evoluído da super ordem Liliiflorae. Exibem características altamente especializadas que servem para atrair insetos e propiciar a polinização cruzada (Dressler 1993). Embora suas flores apresentem uma estrutura relativamente uniforme, a organização de suas partes vegetativas é notavelmente diversa (Dressler 1993), contribuindo para aumentar a variedade de formas de crescimento (Pabst \& Dungs 1975) e conferindo à família um alto poder de adaptação a diferentes ambientes, particularmente ao aéreo (Benzing et al. 1982).

$\mathrm{Na}$ maioria das orquídeas, as folhas dispõem-se disticamente no caule e apresentam venação paralela. Em muitas espécies, a única folha é sustentada pelo caule ou pseudobulbo (Dressler 1981). As folhas, de diferentes formas, podem ser membranosas, coriáceas ou carnosas (Withner et al. 1974) e, quando armazenam água e outras substâncias, são carnosas ou coriáceo-carnosas (Braga 1987).

1. Parte da dissertação de mestrado, de V.C. Oliveira.

2. Departamento de Botânica, IBUNESP, Rio Claro, Caixa Postal 199, 13506-900 Rio Claro, SP. Bolsista do CNPq

3. Autor para correspondência: mgsajo@rc.unesp.br
Embora as primeiras revisões sobre anatomia de Orchidaceae sejam de cunho descritivo (Solereder \& Meyer 1930), atualmente os caracteres anatômicos presentes na família têm sido analisados sob o ponto de vista ecológico/evolutivo, com o intuito de reconhecer o poder adaptativo de seus representantes (Withner et al. 1974, Dressler 1981).

Nas Orchidaceae ocorrem inúmeras adaptações morfológicas e funcionais relacionadas ao epifitismo (Dressler 1981). Uma delas é a presença de epiderme multisseriada nas raízes, o velame, capaz de absorver água e sais minerais, reduzir a transpiração e oferecer proteção mecânica (Pridgeon 1986, Benzing 1987). Outra, é a ocorrência de pseudobulbos que armazenam água e auxiliam na manutenção do balanço hídrico da planta, em situações onde há pouca disponibilidade desse elemento (Braga 1977, 1987). Em muitas espécies epífitas que carecem de pseudobulbos, por exemplo na subtribo Pleurothallidinae, o mesofilo possui células com espessamento espiralado, que armazenam água e evitam o colapso do tecido durante os períodos de dessecação (Pridgeon 1986, Scatena \& Nunes 1996). Adaptações fisiólogicas também são observadas na família sendo comum a ocorrência de metabolismo CAM, que representa um eficiente mecanismo de economia hídrica (Coutinho 1970, Sanders 1979, Braga 1987).

Com o objetivo de indicar caracteres possivelmente relacionados ao hábito epifítico, este estudo 
descreve a estrutura anatômica foliar de nove espécies de orquídeas epífitas, que apresentam hábitos de crescimento variados.

\section{Material e métodos}

O material foi obtido a partir da coleção viva de orquídeas do Instituto de Botânica de São Paulo (IBt), onde se encontra registrado sob a seguinte numeração: Catasetum fimbriatum Lindl. - 3741, Dichaea bryophila Rchb. f. - 13955, Encyclia calamaria (Lindl.) Pabst - 16, Epidendrum campestre Lindl. 7063, Epidendrum secundum Jacq. - 4780D, Miltonia flavescens Lindl. - 6473, Pleurothallis smithiana Lindl. - 607, Stanhopea lietzei (Regel) Schltr. - 3469 e Vanda tricolor Lindl. - 11500.

Essas espécies apresentam hábitos de crescimento diferentes, sendo que em algumas o caule aéreo é desenvolvido e lenhoso (Vanda tricolor e Epidendrum secundum) e em outras ele é reduzido (Pleurothallis smithiana e Dichaea briophyla) ou espessado apenas na região basal, formando pseudobulbos (Catasetum fimbriatum, Stanhopea lietzei, Encyclia calamaria, Miltonia flavescens e Epidendrum campestre).
Para o estudo de cada espécie, selecionaram-se folhas adultas do $3^{\circ}-4^{\circ}$ nós que foram fixadas em FAA 50 e posteriormente transferidas para álcool 50\% (Johansen 1940). No caso de Pleurothallis smithiana a única folha presente foi examinada. Das amostras, retiradas do terço mediano do limbo, foram obtidos cortes histológicos a mão livre, corados com azul de astra e fucsina básica (Roeser 1962). Para a identificação de amido utilizou-se a solução de Lugol (Bücherl 1962); de lignina, solução de floroglucina acidificada (Johansen 1940); dos lipídios, Sudam III (Johansen 1940); de sílica, cristais de fenol (Johansen 1940) e dos flavonóides, hidróxido de potássio (Costa 1982). Os resultados foram registrados através de fotomicrografias, obtidas em fotomicroscópio marca Olympus.

\section{Resultados e Discussão}

As folhas das espécies estudadas apresentam mesofilo homogêneo, feixes vasculares, maiores e menores, intercalados e possuem tamanho variado, dependendo da espécie considerada (tabela 1).

Tabela 1. Caracteres presentes em nove espécies de Orchidaceae. $+=$ presente; $-=$ ausente; ec $=$ espessura de cutícula $(\mu \mathrm{m})$; ea $=$ estômato abaxial c/ poro protegido.

\begin{tabular}{|c|c|c|c|c|c|c|c|c|}
\hline \multirow[t]{3}{*}{ Espécie } & \multirow[t]{3}{*}{ Pseudobulbos } & \multirow{3}{*}{$\begin{array}{l}\text { Dimensões } \\
\text { foliares } \\
\text { comprimento } \\
\text { x largura }(\mathrm{cm})\end{array}$} & \multicolumn{2}{|c|}{$\begin{array}{l}\text { Caracteres relacionados } \\
\text { à reserva de água }\end{array}$} & \multicolumn{4}{|c|}{$\begin{array}{l}\text { Caracteres relacionados à } \\
\text { resistência ao dessecamento }\end{array}$} \\
\hline & & & \multirow[t]{2}{*}{ Epiderme } & \multirow[t]{2}{*}{ Mesofilo } & \multicolumn{2}{|c|}{ Epiderme } & \multirow[t]{2}{*}{ Mesofilo } & \multirow{2}{*}{$\begin{array}{c}\text { Fibras } \\
\text { pericíclicas }\end{array}$} \\
\hline & & & & & $\overline{\mathrm{ec}}$ & $\overline{\text { ea }}$ & & \\
\hline $\begin{array}{l}\text { Encyclia } \\
\text { calamaria }\end{array}$ & + & $13 \times 10$ & - & $\begin{array}{c}\text { hipoderme }+ \\
\text { cristais de } \\
\text { flavonóides }\end{array}$ & $10-15 \mu \mathrm{m}$ & + & $\begin{array}{c}\text { grupos } \\
\text { de células } \\
\text { esclerificadas }\end{array}$ & + \\
\hline $\begin{array}{l}\text { Miltonia } \\
\text { flavescens }\end{array}$ & + & $13 \times 1,5$ & - & hipoderme & $10-15 \mu \mathrm{m}$ & + & $\begin{array}{c}\text { grupos } \\
\text { de células } \\
\text { esclerificadas }\end{array}$ & + \\
\hline $\begin{array}{l}\text { Epidendrum } \\
\text { campestre }\end{array}$ & + & $7 \times 1$ & - & hipoderme & $3-5 \mu \mathrm{m}$ & + & $\begin{array}{c}\text { grupos } \\
\text { de células } \\
\text { esclerificadas }\end{array}$ & + \\
\hline $\begin{array}{l}\text { Stanhopea } \\
\text { lietzei }\end{array}$ & + & $20 \times 8$ & $\begin{array}{l}\text { células adaxiais } \\
\text { desenvolvidas }\end{array}$ & - & $10-15 \mu \mathrm{m}$ & + & $\begin{array}{c}\text { grupos } \\
\text { de células } \\
\text { esclerificadas }\end{array}$ & + \\
\hline $\begin{array}{l}\text { Catasetum } \\
\text { fibriatum }\end{array}$ & + & $19 \times 4,5$ & $\begin{array}{l}\text { células adaxiais } \\
\text { desenvolvidas }\end{array}$ & - & $3-5 \mu \mathrm{m}$ & + & $\begin{array}{c}\text { grupos } \\
\text { de células } \\
\text { esclerificadas }\end{array}$ & + \\
\hline $\begin{array}{l}\text { Epidendrum } \\
\text { secundum }\end{array}$ & - & $9,5 \times 1,5$ & - & hipoderme & $3-5 \mu \mathrm{m}$ & + & $\begin{array}{c}\text { grupos } \\
\text { de células } \\
\text { esclerificadas }\end{array}$ & + \\
\hline $\begin{array}{l}\text { Vanda } \\
\text { tricolor }\end{array}$ & - & $30 \times 3$ & - & - & $10-15 \mu \mathrm{m}$ & + & $\begin{array}{l}\text { esclereídes }+ \\
\text { células } \\
\text { esclerificadas }\end{array}$ & + \\
\hline $\begin{array}{l}\text { Pleurothallis } \\
\text { smithiana }\end{array}$ & is & $6 \times 3$ & - & $\begin{array}{l}\text { hipoderme }+ \\
\text { células com } \\
\text { espessamento } \\
\text { parietal }\end{array}$ & $3-5 \mu \mathrm{m}$ & + & - & + \\
\hline $\begin{array}{l}\text { Dichaea } \\
\text { bryophila }\end{array}$ & - & $2,5 \times 0,4$ & $\begin{array}{l}\text { células adaxiais } \\
\text { desenvolvidas }\end{array}$ & - & $3-5 \mu \mathrm{m}$ & + & - & + \\
\hline
\end{tabular}


As células epidérmicas são recobertas por cutícula, cuja espessura varia de 3-5 $\mu \mathrm{m}$ (figuras 3, 6,7 , tabela 1 ), até $10-15 \mu \mathrm{m}$, (figuras $1,2,8,10,12$, tabela 1). O grau de espessamento da cutícula foi usado como caráter taxonômico por Rosso (1966), que reconheceu na subfamília Cypripedioideae (Orchidaceae) gêneros com folhas plicadas e cutícula fina e gêneros com folhas conduplicadas e cutícula mais espessa. Entretanto, segundo Withner et al. (1974), o padrão de espessamento da cutícula é determinado pela exposição ao sol, sendo que folhas mais expostas tendem a exibir uma cutícula mais espessa nas duas faces.

Dentre as espécies estudadas, aquelas com folhas recobertas por cutícula delgada ocorrem em lugares sombreados enquanto que as demais são características de ambientes ensolarados; essas observações estão de acordo com o sugerido por Withner et al. (1974)

Em corte transversal, as células epidérmicas apresentam-se arredondadas, retangulares, elípticas ou poligonais. Nas folhas de Dichaea bryophila (figura 3), Catasetum fimbriatum (figura 6) e Stanhopea lietzei (figura 8), as células epidérmicas da superfície adaxial são maiores que as da superfície abaxial, como observado em outros representantes da família (Ayensu \& Williams 1972, Mohana-Rao \& Khasim 1987, Stern et al. 1993, Kurzweil et al. 1995). Segundo Kurzweil et al. (1995), células epidérmicas maiores estão relacionadas com a função de reserva de água.

As folhas estudadas são hipoestomáticas e os estômatos ocorrem no mesmo nível das demais células epidérmicas, ou em posição ligeiramente elevada (figuras 18-20). Segundo Rasmussen (1987) os estômatos em Orchidaceae raramente são aprofundados, mas exibem outros caracteres xeromórficos. Nas espécies estudadas, as células-guarda mostram um espessamento parietal desenvolvido, na região de contato entre elas, conferindo um aspecto triangular ao lúmen; ocorrem também projeções sobre o poro estomático, formando câmaras supraestomáticas (figuras 18-20). A presença de câmaras supraestomáticas, que mantêm um pequeno compartimento de ar úmido reduzindo a transpiração, é uma característica comum em orquídeas epífitas, que enfrentam altas temperaturas e pouca disponibilidade de água (Rosso 1966, Rasmussen 1987).
Tricomas glandulares, situados em depressões na epiderme, somente estão presentes nas duas superfícies da folha de Stanhopea lietzei (figura 21).

$\mathrm{Na}$ folha de Pleurothallis smithiana (figura 15), adjacente à epiderme, ocorrem 1-3 camadas de células aclorofiladas, diferentes das células retangulares e elípticas do clorênquima. Em Epidendrum campestre (figura 4), E. secundum (figura 5) e Encyclia calamaria (figura 12) observa-se uma camada subepidérmica adaxial formada por células mais desenvolvidas. Em Miltonia flavescens (figuras 10-11), as células subepidérmicas da região adaxial possuem paredes espessadas e são anticlinalmente alongadas na região central da lâmina (figura 10).

Hipoderme de células desenvolvidas é freqüente nas Orchidaceae (Pridgeon 1986), tendo sido descrita para Palumbina candida, Odontoglossum convallarioides e Odontoglossum egertonii (Ayensu \& Williams 1972), para Bulbophyllum andersonii (Mohana-Rao \& Khasim 1987) e para espécies de Dresslerella (Pridgeon \& Williams 1979), de Myoxanthus (Pridgeon \& Stern 1982) e de Bletiinae (Khasim \& Mohana-Rao 1990).

A hipoderme é considerada a estrutura mais comum para armazenamento foliar de água, estando presente em espécies epífitas de Gesneriaceae, Ericaceae, Clusiaceae, Araliaceae, e Bromeliaceae (Madison 1977). Segundo Haberlandt (1914) e Madison (1977), além de armazenar água, a hipoderme exerce um papel importante na economia de calor, especialmente nas epífitas com metabolismo CAM.

Em todas as folhas estudadas, o clorênquima é homogêneo, não diferenciado em parênquima paliçádico e lacunoso e suas células podem apresentar aspecto arredondado (figura 3), poligonal (figura 5), elíptico (figura 12) e retangular (figura 15), em corte transversal. Em Encyclia calamaria, encontram-se idioblastos com ráfides (figura 14), que podem estar relacionados ao balanço iônico e osmoregulação da planta (Bonates 1993); ocorrem também cristais de flavonóides, como em outras espécies do gênero (Pabst et al. 1980). Os flavonóides, além de protegerem contra herbivoria, associam-se aos radicais livres, freqüentes em plantas que vivem sob algum tipo de estresse (Yamasaki et al. 1997).

No mesofilo de Pleurothallis smithiana observam-se grãos de amido e células com espessamentos 

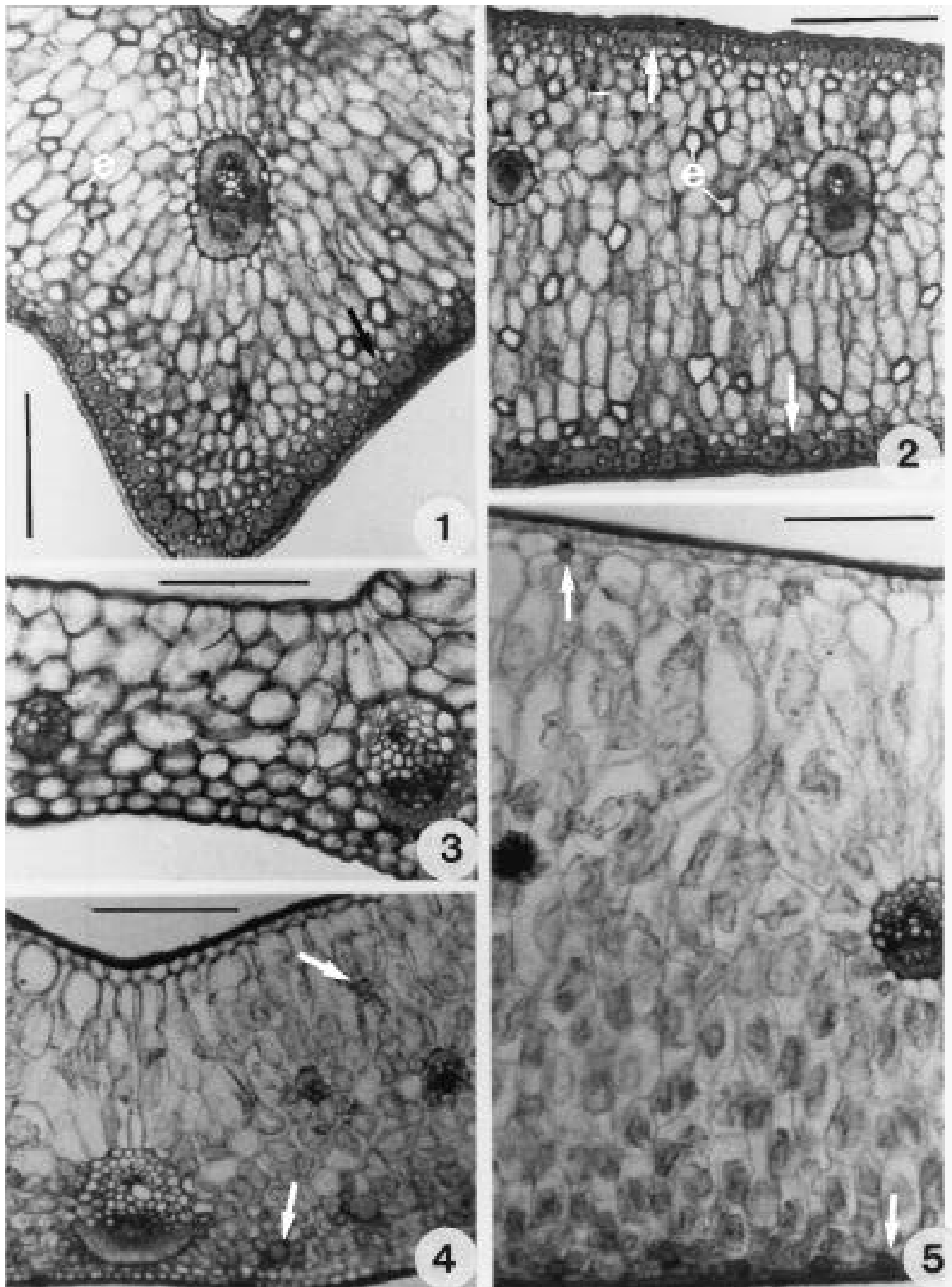

Figuras 1-5. Cortes transversais de folhas. 1-2. Vanda tricolor, com esclereídes no mesofilo (e) e fibras em posição subepidérmica (setas). 3. Dichaea bryophila - aspecto geral. 4. Epidendrum campestre, com grupos de fibras em posição subepidérmica (setas). 5. Epidendrum secundum, com hipoderme adaxial e grupos de fibras não associados aos feixes vasculares (setas). Escalas: 1, 2, 4, $5=$ $250 \mu \mathrm{m} ; 3=100 \mu \mathrm{m}$. 


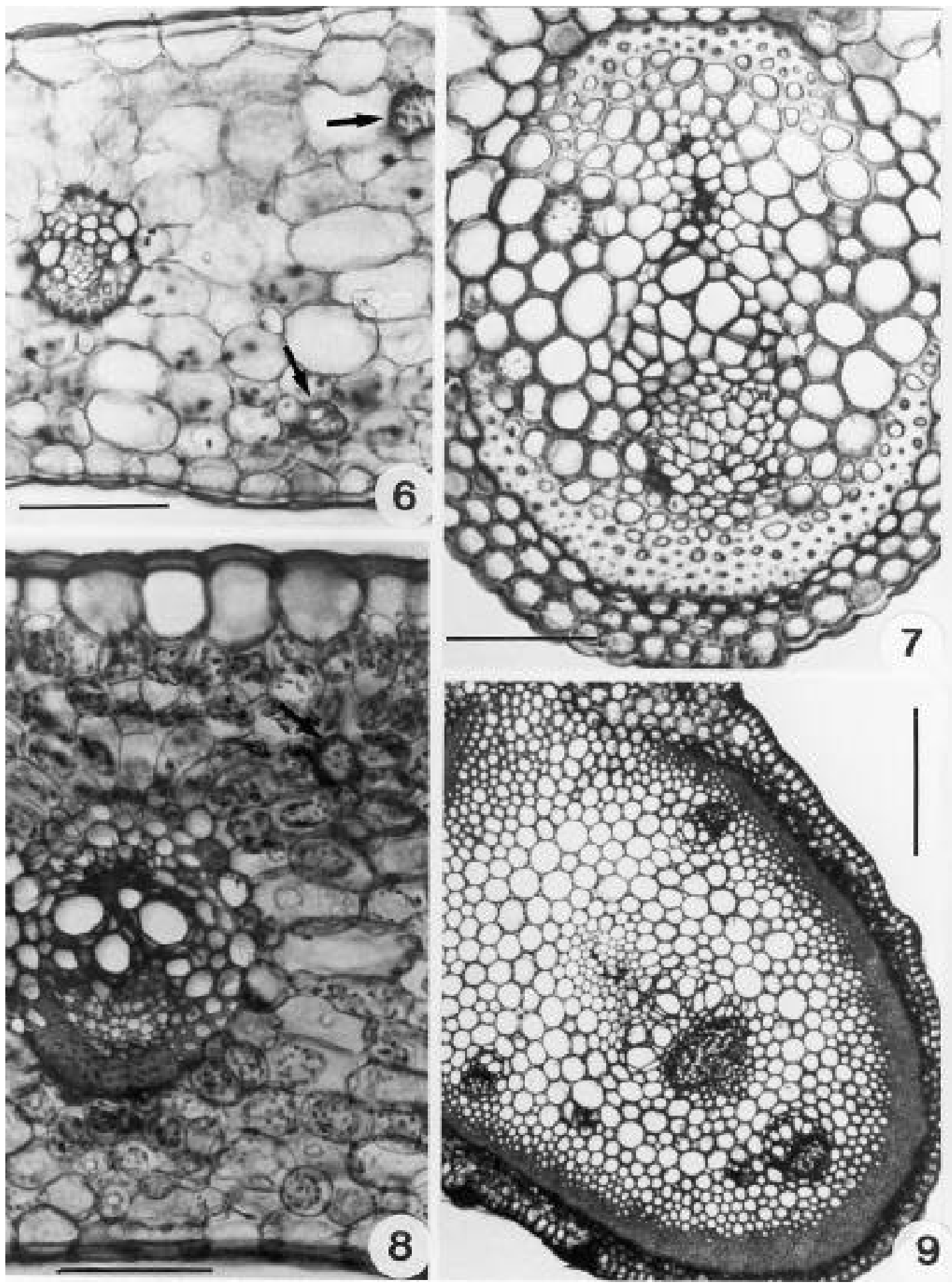

Figuras 6-9. Cortes transversais de folhas. 6-7. Catasetum fimbriatum. 8-9. Stanhopea lietzei. No mesofilo das duas espécies observamse grupos de fibras não associados aos feixes vasculares (setas). Escalas: $6=50 \mu \mathrm{m} ; 7,8=100 \mu \mathrm{m} ; 9=250 \mu \mathrm{m}$. 

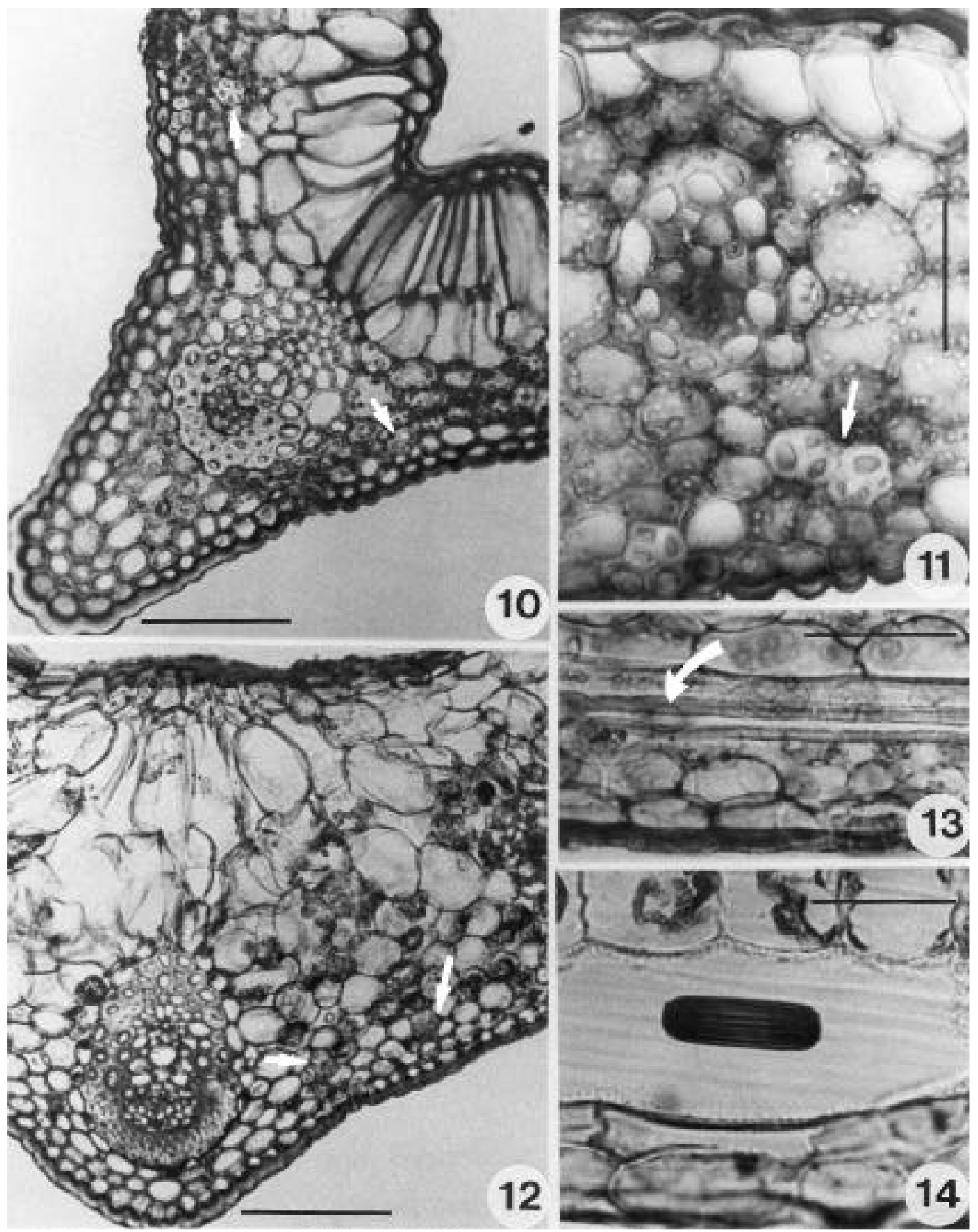

Figuras 10-14. Cortes de folha. 10-11. Miltonia flavescens, em corte transversal, com hipoderme na face adaxial e grupos de fibras na face abaxial (setas); 12-14. Encychia calamaria. 12. Corte transversal mostrando hipoderme adaxial e grupos de fibras na região abaxial (setas). 13-14. Cortes longitudinais mostrando, respectivamente, fibras associadas à sílica e idiblasto com ráfides na região abaxial. Escalas: 10, $12=100 \mu \mathrm{m} ; 11,13,14=50 \mu \mathrm{m}$. 

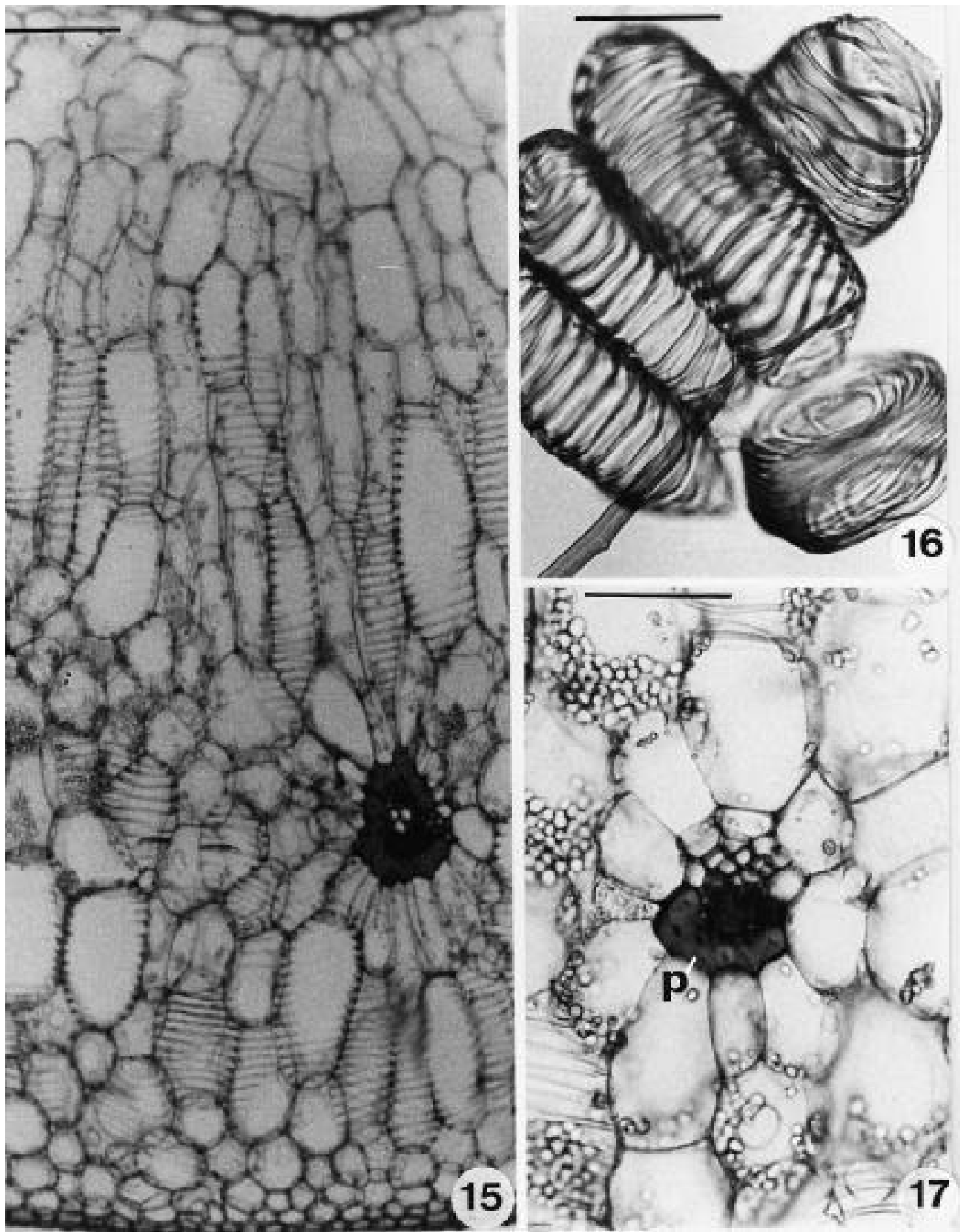

Figuras 15-17. Pleurothalis smithiana. 15. Aspecto geral de corte transversal da folha. 16. Células do mesofilo com espessamento parietal secundário em espiral. 17. Feixe vascular com células pericíclicas esclerificadas (p), adjacentes ao floema. Escalas: $15=$ $250 \mu \mathrm{m} ; 6,17=100 \mu \mathrm{m}$ 
parietais secundários em espiral (figuras 15-16), semelhantes às descritas para outras Orchidaceae (Foster 1956, Olatunji \& Nengim 1980, Pridgeon 1982, Bonates 1993, Scatena \& Nunes 1996) e algumas Agavaceae (Koller \& Rost 1988). A função dessas células, segundo os autores, estaria relacionada à retenção de água e ao suporte mecânico, evitando o colapso celular durante a dessecação. Tais células são, também, similares às encontradas no córtex radicular de Pleurothallis smithiana, Catasetum fimbriatum e Stanhopea lietzei e nos pseudobulbos de Pleurothallis smithiana, Catasetum fimbriatum e Encyclia calamaria (Oliveira \& Sajo, dados não publicados).

Grupos de células esclerificadas, adjacentes às duas superfícies, são observados nas folhas da maioria das espécies estudadas (figuras 4, 5, 6, 8, setas), estando presentes unicamente na região abaxial em
Miltonia flavescens (figuras 10, 11, 18, setas) e Encyclia calamaria (figura 12, seta). Esses grupos são formados por 3-14 células que, na maioria das espécies, encontram-se associadas a corpos de sílica (figura 13). Em Vanda tricolor ocorrem esclereídes isoladas, distribuídas esparsamente no mesofilo e células esclerificadas em posição subepidérmica (figuras 1, 2, 19, setas).

Por possuírem grupos de células esclerificadas, que conferem resistência mecânica em casos de desidratação, a maioria das folhas estudadas é comparável às folhas coriáceas, referidas por Withner et al. (1974). Segundo os mesmos autores, esse tipo de folha em Orchidaceae, é característico de formas vegetativas mais evoluídas, que possuem pseudobulbos e são capazes de sobreviver em habitats xéricos. Todas as espécies estudadas, portadoras de folhas coriáceas, apresentam pseudobulbos (tabela 1),
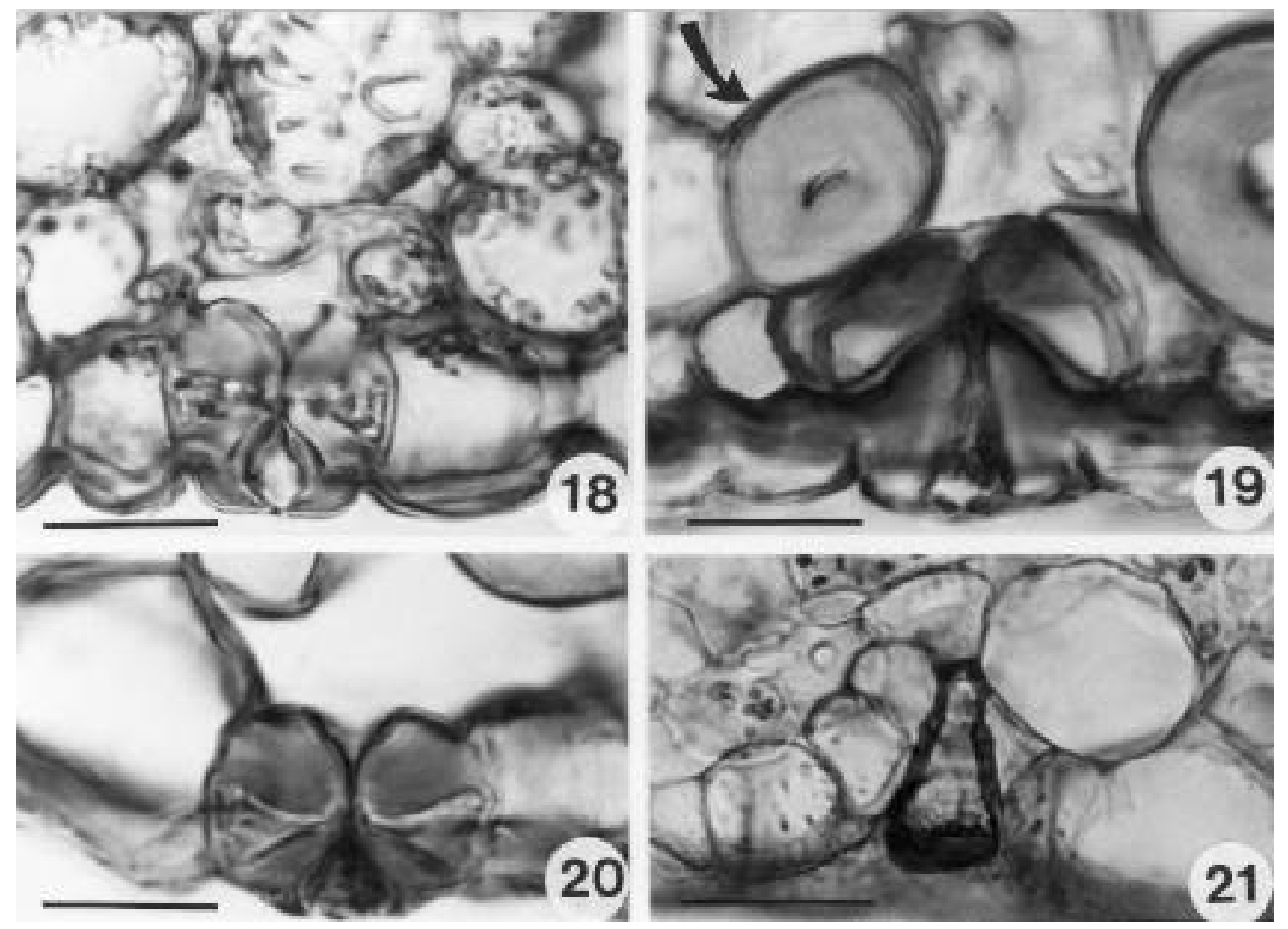

Figuras 18-20. Cortes transversais de folhas mostrando estômatos com células guarda de lúmem triangular e câmara supraestomática na região abaxial. 18. Miltonia flavescens. 19. Vanda tricolor. 20. Catasetrum fimbriatum. 21. Corte transversal de folha de Stanhopea lietzei mostrando tricoma glandular na face abaxial. Escalas: 18, 19, $20=20 \mu \mathrm{m} ; 21=50 \mu \mathrm{m}$. 
exceto Vanda tricolor e Epidendrum secundum, que possuem caules desenvolvidos.

Dichaea bryophila não possui pseudobulbo e suas folhas são membranáceaes e reduzidas (tabela 1), não apresentando células esclerificadas no mesofilo (figura 3). Pleurothallis smithiana, que também não apresenta pseudobulbo (tabela 1), possui mesofilo suculento devido à ocorrência de células com espessamento parietal secundário espiralado (figuras 15-16).

Em todas as folhas estudadas, os feixes vasculares são colaterais mas observam-se, ocasionalmente, feixes menores anfivasais (figura 11) resultantes possivelmente da fusão de feixes colaterais, conforme observado em outras monocotiledôneas (Castro \& Menezes 1995, Sajo 1992). Células esclerificadas de origem pericíclica podem envolver completamente os feixes vasculares (figuras 1-2,15), ou estarem presentes apenas na região adjacente ao floema (figura 17). As células da endoderme, que envolvem os feixes vasculares, são menores que as células do mesofilo e tendem a uma disposição radial em torno do feixe vascular (figuras $2,5,15$ ).

A nervura central das folhas de Catasetum fimbriatum (figura 7) e Stanhopea lietzei (figura 9) é bastante proeminente na face dorsal. Em Stanhopea lietzei, ela é constituída por um feixe central maior e três marginais menores, imersos numa matriz parenquimática; ocorrem 3-4 camadas de fibras na região adaxial e na, face inferior, a nervura é circundada por 8-10 camadas de fibras dispostas em forma de U (figura 9).

A análise das folhas estudadas (tabela 1), mostra a ocorrência de caracteres que podem ser interpretados como adaptações à economia de água, elemento escasso para plantas de hábito epifítico. Todas elas são hipostomáticas, exibem estômatos com poro protegido por projeções e feixes vasculares envolvidos por fibras pericíclicas. No mesofilo de Pleurothallis smithiana observa-se hipoderme nas duas faces e células com espessamento parietal lignificado, conferindo ao órgão um aspecto de suculência; uma vez que $P$. smithiana possui somente um caule reduzido sustentando uma única folha, este órgão deve representar a principal estrutura armazenadora de água da planta. As folhas de Dichaea bryophila são reduzidas, recobertas por cutícula delgada e não apresentam células esclerificadas no mesofilo; nelas observam-se ape- nas células epidérmicas adaxiais mais desenvolvidas, que provavelmente auxiliam na reserva de água. Os demais representantes, portadores de folhas coriáceas, possuem células esclerificadas no mesofilo, que conferem resistência mecânica em casos de desidratação; exibem, ainda, caracteres possivelmente relacionados à economia hídrica, tais como epiderme adaxial desenvolvida (Catasetum fimbriatum e Stanhopea lietzei) e hipoderme adaxial (Encyclia calamaria, Epidendrum campestre e Miltonia flavescens). A presença de cristais de flavonóides, no mesofilo de Encyclia calamaria, também pode estar relacionada à existência de um estresse hídrico, no ambiente ocupado pela planta.

Agradecimentos - Ao Dr. Fábio de Barros por ter fornecido e identificado o material.

\section{Referências bibliográficas}

AYENSU, E.S. \& WILLIAMS, N.H. 1972. Leaf anatomy of Palumbina and Odontoglossum, subgenus Osmoglossum. American Orchid Society Bulletin 41:687-696.

BENZING, D.H. 1987. Vascular epiphytism: taxonomy participation and adaptative diversity. Annals of the Missouri Botanical Garden 74:183-204.

BENZING, D.H., OTT, D.W. \& FRIEDMAN, W.E. 1982. Roots of Sobralia macrantha (Orchidaceae): structure and function of the velamen-exodermis complex. American Journal of Botany 69:608-614.

BONATES, L.C.M. 1993. Estudos ecofisiológicos de Orchidaceae da Amazônia II. Anatomia ecológica foliar de espécies com metabolismo CAM de uma campina da amazonia central. Acta Amazonica 23:315-348.

BRAGA, P.I.S. 1977. Aspectos ecofisiológicos de Orchidaceae da Amazonia II. Anatomia ecológica foliar de espécies com metabolismo CAM de uma campina da amazonia central. Acta Amazonica 7:1-89.

BRAGA, P.I.S. 1987. Orquídeas. Biologia floral. Ciência Hoje 5:53-55.

BÜCHERL, W. 1962. Técnica microscópica. Polígono, São Paulo.

CASTRO, N.M. \& MENEZES, N.L. 1995. Anatomia foliar de espécies de Paepalanthus. Acta Botanica Brasilica 9:213-219.

COSTA, A.F. 1982. Farmacognosia. 2. ed. Fundação Calouste Gulbenkian, Lisboa.

COUTINHO, L.M. 1970. Sobre a assimilação noturna de $\mathrm{CO}_{2}$ em orquídeas e bromélias. Ciência e Cultura 22:364-368.

DRESSLER, R.L. 1981. The orchids: natural history and classification. Harvard University Press, Cambridge.

DRESSLER, R.L. 1993. Phylogeny and classification of the orchid family. Dioscorides Press, Portland.

FOSTER, A.S. 1956. Plant idioblasts: remarkable example of cell specialization. Protoplasma 46:184-193.

HABERLANDT, G.F.J. 1914. Physiological plant anatomy. MacMillan \& Co., London.

JOHANSEN, D.A. 1940. Plant Microtechnique. McGraw Hill, New York. 
KHASIM, S.M. \& MOHANA-RAO, P.R. 1990. Anatomy in relation to taxonomy in some members of Epidendroideae (Orchidaceae). Phytomorphology 40:243-250.

KOLLER, A.L. \& ROST, T.L. 1988. Structural analysis of waterstorage tissue in leaves of Sansevieria (Agavaceae). Botanical Gazette 149:260-274.

KURZWEIL, H., LINDER, H.P., STERN, W.L. \& PRIDGEON, A.M. 1995. Comparative vegetative anatomy and classification of Diseae (Orchidaceae). Botanical Journal of the Linnean Society 117:171-220.

MADISON, M. 1977. Vascular epiphytes: their systematic occurrence and salient features. Selbyana 2:1-13.

MOHANA-RAO, P.R. \& KHASIM, S.M. 1987. Anatomy of three species of Bulbophyllum (Orchidaceae) with comments on their ecological adaptability and taxonomy. Proceedings of the Indian Academy of Sciences 97:391-397.

OLATUNJI, O.A. \& NENGIM, R.O. 1980. Occurrence and distribution of tracheoidal elements in the Orchidaceae. Botanical Journal of the Linnean Society 80:357-370.

PABST, G.F.J. \& DUNGS, F. 1975. Orchidaceae Brasiliensis I. Kurt Schmersow, Hildesheim.

PABST, G.F.J., MOUTINHO, J.L.A. \& PINTO, A.V. 1980. Reestabelecimento do gênero Anaecheillium Hoffmg. e revisão do gênero Hormidium Lindl. ex Heynh. In Anais do $1^{\circ}$ Encontro de Orquidófilos e Orquidólogos. Expressão e Cultura, Rio de Janeiro, p.73-85.

PRIDGEON, A.M. 1982. Diagnostic anatomical characters in the Pleurothallidinae (Orchidaceae). American Journal of Botany 69:921-938.

PRIDGEON, A.M. 1986. Anatomical adaptations in Orchidaceae. Lindleyana 1:90-101.

PRIDGEON, A.M. \& WILLIAMS, N.H. 1979. Anatomical aspects of Dresslerella (Orchidaceae). Selbyana 5:120-134.
PRIDGEON, A.M. \& STERN, W.L. 1982. Vegetative anatomy of Myoxanthus (Orchidaceae). Selbyana 7:55-63.

RASMUSSEN, H. 1987. Orchid stomata - structure, differentiation, function, and phylogeny. In Orchid biology: reviews and perspectives, IV (J. Arditti, ed.). Cornell University Press, New York, p.105-138.

ROESER, K.R. 1962. Die nadel der schwarzkiefer massenprodukt und kunstwerk der natur. Mikrokosmos 61:33-36.

ROSSO, S.W. 1966. The vegetative anatomy of the Cypripedioideae (Orchidaceae). Journal of the Linnean Society (Botany) 59:309-341.

SANDERS, D.J. 1979. Crassulacean Acid Metabolism and its possible occurrence in the plant family Orchidaceae. American Orchid Society Bulletin 48:796-798.

SAJO, M.G. 1992. Estudos morfoanatômicos em órgãos foliares de Xyris L. (Xyridaceae). Boletim de Botânica da Universidade de São Paulo 12:67-86.

SCATENA, V.L. \& NUNES, A.C. 1996. Anatomia de Pleurothallis rupestris Lindl. (Orchidaceae) dos campos rupestres. Boletim de Botânica da Universidade de São Paulo 15:35-43.

SOLEREDER H. \& MEYER, F. 1930. Systematiche anatomie der Monokotyledonen. Verlag von Gebruder Borntraeger, Berlin.

STERN, W.L., MORRIS, M.W. \& JUDD, W.S. 1993. Comparative vegetative anatomy and systematics of Spiranthoideae (Orchidaceae). Botanical Journal of the Linnean Society 113:161-197.

WITHNER, C.L., NELSON, P.K. \& WEJKSNORA, P.J. 1974. The anatomy of orchids. In The Orchids: scientific studies (C.L. Withner, ed.). John Wiley, New York, p.267-334.

YAMASAKI, H., SAKIHAMA, Y. \& IKEHARA, N. 1997. Flavonoid-peroxidase reaction as detoxification mechanism of plant cell against $\mathrm{H}_{2} \mathrm{O}_{2}$. Plant Physiology 19:481-486. 